\title{
Entrevista com o Prof. Dr. Josep Fontana.
}

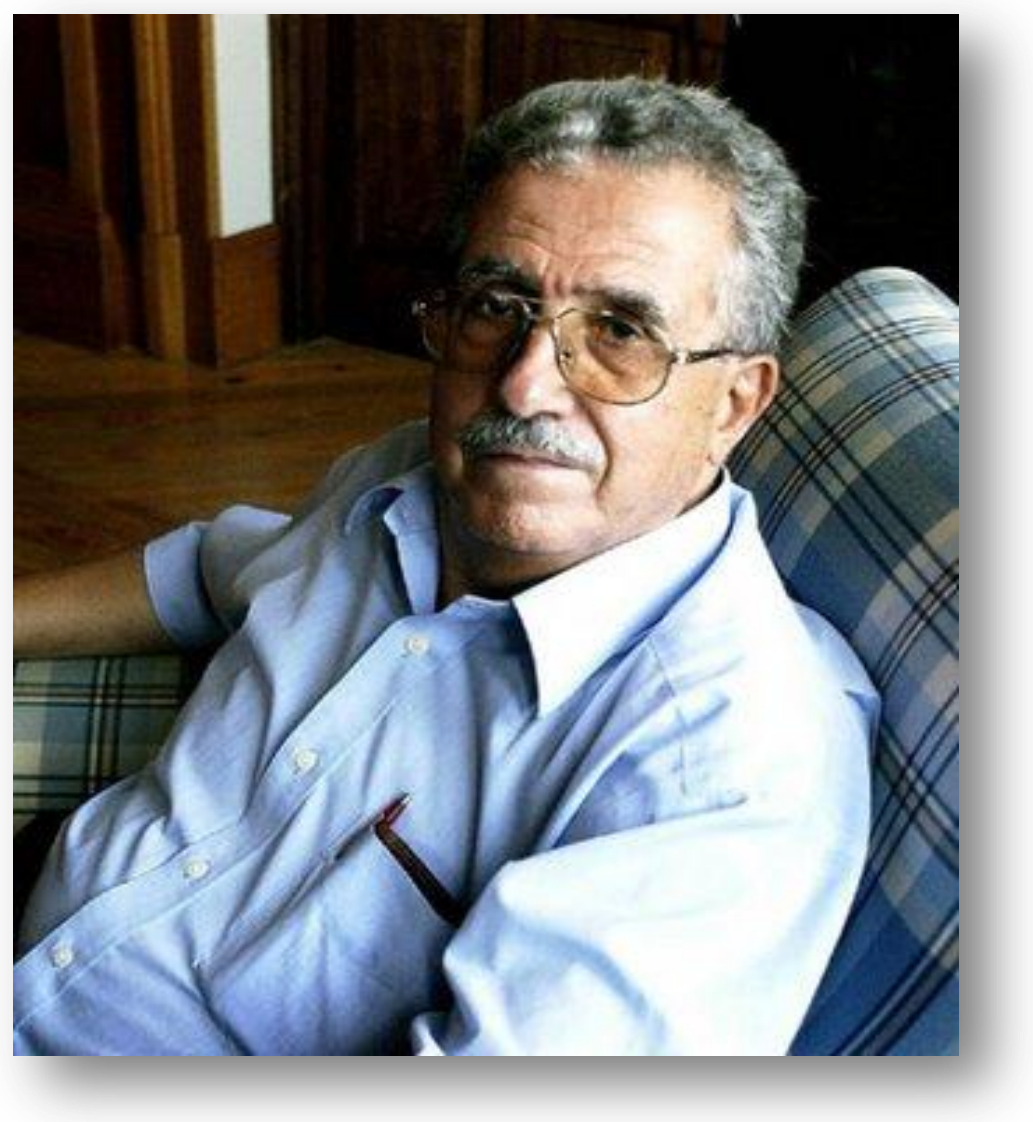

Foto: Blog Lorenzo Doreste

Josep Fontana i Lazaro nasceu em 1931, formou-se em História na Universidade de Barcelona e doutorou-se na mesma instituição em 1970. Foi professor, entre outras áreas, de História da Espanha (séculos XIX e XX) e História Econômica, na Universidade de Barcelona, na Universidade Autônoma de Barcelona e na Universidade de Valência. Entre suas obras publicadas no Brasil encontramos História: análise do passado e projeto social,

\footnotetext{
* Professor do Departamento de Historia da UFSC, estagiário de pós-doutorado junto ao Departamento de
} Historia Moderna i Contemporanea da Universitat Autonoma de Barcelona, bolsista da CAPES em 2010. 
Introdução ao Estudo da História Geral, A Europa diante do Espelho, A História dos Homens e A História depois do Fim da História, todos publicados pela Edusc, de Bauru. Foi um dos fundadores e é membro do conselho da Editora Crítica, de Barcelona. Escreve semanalmente no periódico alternativo eletrônico Sin Permiso (http://www.sinpermiso.info/). Atualmente, Fontana trabalha no Instituto Jaume Vicens i Vives, que parece um bunker do conhecimento, no andar mais alto do prédio da Universidade Pompeu Fabra, nas bordas do bairro Gótico, no acolhedor centro de Barcelona, muito perto da Vila Olímpica e do antigo porto, hoje revitalizado. O Instituto possui uma grande área física, ocupada por extensa biblioteca (lotada de alunos de graduação e pósgraduação), em grande parte formada por doação do acervo pessoal (37 mil livros, monografias e teses) do professor Fontana. Na manhã do dia 2 de junho de 2010 ele gentilmente concedeu esta entrevista:

Pergunta: Como foi sua experiência de estudar e formar-se como historiador durante o Franquismo? Como era o ambiente universitário?

Josep Fontana: Se alguma coisa poderia fazer sentido naquela época, era estudar a História. Foi um tempo em que se faziatodo o possível para o passado ser negado, esquecido e desfigurado. O esforço para recuperar o passado tinha um sentido muito além da importância acadêmica, tinha um valor cívico. Eu me formei com o Professor Jaume Vicens i Vives (1910-1960) e tenho aqui até hoje uma carta em que ele afirma que a História é importante, a Universidade também é importante, mas mais importante que tudo é o País. $E$ se pode servir ao País através da ciência histórica, com o trabalho de influir sobre a consciência coletiva das pessoas. Vives foi muito importante em minha formação inicial. Então, estudar história num meio tão hostil como o Franquismo era um estímulo, um desafio. Isto também tomou muito impulso com a minha convivência com Pierre Vilar, que defendia que o historiador tem uma responsabilidade sobre a consciência coletiva. Além disso, eu estava envolvido com uma militância clandestina, que era outra forma de lutar.

Pergunta: No Brasil, Jaume Vicens i Vives é pouco conhecido. Qual a importância deste historiador para a Espanha e para a Catalunha?

Josep Fontana: Vicens i Vives era um dos poucos historiadores espanhóis que, na época de sua atuação, estava em sintonia com outros historiadores do resto do mundo, como afirmava Raymond Carr [historiador inglês especialista em História e Historiografia Espanhola]. Era um medievalista especializado nos séculos XV e XVI. Mas num determinado momento, fez uma viragem na carreira e insistiu na importância da História Contemporânea. Era muito comum naquela época, tanto na Catalunha como no restante da Espanha, a noção de que a história só deveria estudar até o final do Antigo Regime. Vicens i Vives defendeu o estudo dos séculos XIX e XX, quando a Catalunha foi palco de intensas lutas políticas e sociais. Isto era visto pelos conservadores como antipatriótico. Além disso, Vives desenvolveu um 
trabalho muito sério em história econômica, em escala global, publicando um primeiro manual de história econômica [Historia social y econômica de España y América. Barcelona: Teide, 1957] que por muitos anos influiu na formação de historiadores e economistas. A morte de Vives foi uma tragédia; ele morreu muito cedo, tinha apenas 50 anos. Certamente teria ainda muitos anos de abundante produção. Meu trabalho de graduação, sobre a segunda metade do século XVII [El Comercio exterior de Barcelona en la segunda mitad del siglo XVII, 1664-1699] foi em parte sugerido e estimulado por ele; minha tese doutoral sobre a queda do Absolutismo [La Quiebra de la Monarquía Absoluta, 1814-1820 : la crisis del Antiguo Régimen en España], também teve o estímulo dele.

Pergunta: Em sua tese de doutorado, sobre a quebra da Monarquia Absoluta, além da reconstrução dos conflitos políticos "do alto" da sociedade, há homens pobres, camponeses, que intervêm nos eventos. Quais são as dificuldades para estudar os "de baixo" nas fontes escritas geralmente pelos "de cima"?

Josep Fontana: Isto é um problema permanente. Mas sempre conseguimos depoimentos e testemunhos de camadas médias, de setores sociais que não são somente os "de cima". Detalhando mais, há tesouros de fontes muito importantes, que mal foram estudados, como, por exemplo, a correspondência particular das pessoas. O que não podemos esquecer é que a pesquisa histórica não deve apenas levantar os acontecimentos e colocá-los numa sequência cronológica para explicar como chegamos até hoje, pois isso provoca uma sucessão inevitável de eventos, como um encadeamento predeterminado. Devemos entender que, a cada momento, as expectativas de futuro estão abertas, e são muitas. Não há nenhuma certeza de como as coisas vão se desenvolver, de quem tem razão. Aí é que reside a questão: devemos procurar, em cada época, o que as pessoas pensam e entender o que desejam. Entender as ilusões nas quais acreditam, os erros que cometem, os temores que os conduzem a fazer coisas que podemos considerar disparatadas. Eu tive a sorte de trabalhar com um bom material produzido pelos "de cima", as Atas do Conselho de Ministros, as Atas do Conselho de Estado e os Diários das Sessões das Cortes [parlamento espanhol], que são fontes riquíssimas e expressavam o que os grupos dominantes comentavam e pensavam. Bem diferente do que eles publicavam. É muito importante saber como pensam os "de cima". É importante saber como percebem e decidem certas coisas, em outras dimensões. No século XIX temos outra vantagem, que é a existência da imprensa e sua inserção social em muitas camadas além do grupo dominante. Há uma grande literatura popular, baseada em romances. Há acervos com diários e cartas particulares, de pessoas comuns, o que é muito importante para se investigar o que as pessoas estavam pensando. Para mim isso foi fundamental para entender o sentimento dos pequenos proprietários camponeses ante um movimento como o Carlismo [movimento político liderado por forças ligadas ao Antigo Regime contra políticos constitucionais, em torno de linhas sucessórias ao trono espanhol]. Um pesquisador localizou uma caixa de cartas e diários, de uma família camponesa, onde mostra e interpreta a evolução da atuação deles. 
Com essa documentação é possível avaliar o que sentiam a cada momento. Num primeiro momento, os camponeses reagem às políticas liberais, que resultavam em aumento de impostos. Então esses grupos de guerrilheiros vão subsistindo com o dinheiro que recebiam de sacerdotes e de monastérios. Quando este dinheiro termina, passam a saquear as populações. Praticam roubos, sequestros, ameaçam matar o gado. Não vivem mais como simples camponeses. Precisam sobreviver entre a fome e a ação dos arrecadadores do Estado. Isto me recorda uma situação semelhante, quando houve a Guerra Civil Russa [19171921], logo no início da Revolução Bolchevique. Um político britânico perguntou a um camponês quem ele desejava que ganhasse a guerra, os "vermelhos" ou os "brancos"? Ele respondeu: os que roubarem menos! Então é preciso compreender o que move as pessoas a cada momento. Estes conflitos são complexos. Não basta entendermos as leis, os discursos, as proclamações oficiais, se não conseguirmos nos aproximar e compreender como as pessoas estão agindo.

Pergunta: O Carlismo foi claramente um movimento contrarrevolucionário. Mas será que podemos considerar a ação dos camponeses na primeira [1833-1840] e segunda [1846-1849] guerras carlistas como parte deste processo contrarrevolucionário? A historiografia atual parece não considerar essas especificidades. O senhor mesmo sempre defendeu um espaço importante de autonomia camponesa nestas lutas durante a primeira metade do século XIX. Como o senhor avalia esta questão?

Josep Fontana: Inicialmente, devemos compreender que em um movimento que parte do alto se agregam pessoas com os mais diferentes objetivos. São promessas de felicidade, de um governo justo, sem abusos. Mas os que vêm de baixo possuem ideias e projetos próprios, e num momento determinado, quando o inimigo comum está derrotado, passam a defender suas próprias ideias abertamente, como já aconteceu muitas vezes. No caso da chamada segunda guerra carlista - mais restrita a Catalunha, Valência e País Basco -, é preciso se entender a complexidade do movimento: ao lado da ideologia conservadora carlista, havia ideias republicanas e revolucionárias de 1848 e tudo isto convivia com as dificuldades de vida do campesinato. Depois da Revolução de 1868 [com a instalação da 1.a República], Fernando Garrido [intelectual republicano e socialista] registrou o depoimento de um antigo guerrilheiro da segunda guerra carlista: em todo o Ampurdán [região próxima dos Pirineus e da fronteira francesa] se podia facilmente recrutar guerrilheiros para o Carlismo ou para a República. Para a República, por um "duro" [moeda espanhola de baixo valor]; para a Monarquia, por dois "duros". Na segunda guerra carlista há momentos nos quais republicanos lutam ao lado de carlistas contra os monarquistas constitucionais. Ao longo do movimento os camponeses vão cada vez mais se identificando com o republicanismo e cada vez menos com o carlismo. Há regiões, como o sul, a Andaluzia, onde o carlismo nunca foi forte. Esses temas devem ser estudados região por região. Mas o que é importante é tentar compreender as ações dos "de baixo" em seus termos, que nem sempre são os termos dos "de cima". Isto nos dá um panorama muito mais complexo. 
Pergunta: Em sua carreira, o senhor trabalhou com dois historiadores muito influentes no Brasil: Pierre Vilar e Edward Thompson. Como foi sua experiência com eles?

Josep Fontana: Tive três importantes mestres. O primeiro foi Ferran Soldevila, historiador republicano catalão, que dava aulas clandestinas, na sua casa, depois de voltar do exílio. Era um antifranquista que tinha de se pronunciar com muito cuidado. $O$ segundo mestre foi Jaume Vicens i Vives, na Universidade de Barcelona. Apesar de não termos as mesmas idéias políticas - Vives era mais moderado, e eu era mais a esquerda -, compartilhava sua visão de história como algo importante para o País. Ao longo de meu curso na Universidade, durante o doutorado, quando eu comecei a trabalhar com várias questões do século XIX, Vives não se sentia habilitado para acompanhar e me indicou para Pierre Vilar, que foi meu terceiro mestre. Vilar foi um grande amigo e interlocutor; troquei correspondência com ele até sua morte. Tivemos muitas conversações ótimas, conversávamos mais sobre o presente do que sobre o passado, sobre diversos assuntos do mundo atual. Ele sempre foi muito gentil e atencioso. Ele lia o que eu escrevia e me enviava seus textos também. Foi uma relação muito enriquecedora. Com Thompson foi diferente. Para mim ele foi um descobrimento. Conheci o livro dele, The making of the English working class, obra impactante, que teve uma primeira edição espanhola que foi muito malfeita, um desastre. Depois tive oportunidade de conhecê-lo pessoalmente, entrevistei-o sobre sua trajetória intelectual e política, sobre as experiências do irmão dele [Frank Thompson, capturado e fuzilado pelos nazistas na Bulgária, em 1944], e conversávamos sobre o que poderia ter sido a Europa do Pós-Guerra com a derrota do fascismo. Uma Europa que poderia ter sido muitas coisas, mas não foi. Porém meu contato com Thompson foi muito tardio, eu já era um historiador formado. Mas nos identificávamos em muitos sentidos, na visão de história e na visão política. É preciso lembrar que Thompson sempre se manteve muito independente, sempre caminhou contra a corrente, nunca se deixou enredar no senso comum ou no discurso da moda. Ele tinha um diálogo direto com estudantes e trabalhadores, principalmente na sua campanha pela paz [contra a instalação de bases militares com armas nucleares norte-americanas na Europa ocidental, movimento muito forte nos anos 1980]. Depois passamos muito trabalho numa segunda tradução espanhola de La Formación de La Clase Obrera em Inglaterra [Barcelona: Ed. Critica, 1989]. Trabalhei com muito cuidado com um colega historiador, depois pedimos ajuda a um catedrático inglês que trabalhava na Universidade de Barcelona, mas havia palavras e expressões que nem este inglês conhecia. Ao final, enviamos uma lista com algumas interrogações ao próprio Thompson. Foi um desafio muito difícil traduzi-lo ao castelhano. Sempre admirei a firmeza de conviç̧ões dele. Quando houve os movimentos de 1968, e suas repercussões teóricas na historiografia, com a chamada "viragem linguística", que ficou tão famosa nos anos subsequentes, Thompson manteve suas convicções e continuou produzindo importantes trabalhos. 
Pergunta: Em seu livro La Historia después del fin de la Historia há uma forte defesa de uma história critica e uma série de argumentos contrários às teses da pós-modernidade. Como o senhor avalia o cenário historiográfico na atualidade?

Josep Fontana: Quando se produz a viragem que levou ao predomínio da História Cultural e depois dos pós-modernismos, é evidente que há um momento no qual a crítica se assenta na denúncia de aspectos débeis, num conjunto de erros praticados pela historiografia anterior. Isto foi positivo. A historiografia anterior trabalhava com catecismos e visões esquemáticas muito ruins. Usavam-se esquemas simplificados, de um marxismo muito primário de "superestruturas" e "infraestruturas", deixando-se de lado elementos dinâmicos. Neste sentido, a virada pós-moderna foi útil, depurou a história de práticas esquemáticas pobres. No entanto, os pós-modernos ficaram presos nas mesmas críticas que fizeram desde o início e hoje seguem publicando o mesmo que publicaram há 10 ou 15 anos. Não há nenhuma mostra do tipo de história que tinham prometido. Há um momento em que você precisa fazer com que a crítica historiográfica pare de demolir e passe a construir algo que seja uma nova produção, que reconstrua uma história social. Isto continua sendo necessário. Porque o que se faz deve ter utilidade para entender o mundo em que vivemos, ou não serve para nada; ou as pessoas devem optar por se dedicar a atividades socialmente mais úteis [risos].

\section{Pergunta: O que o senhor considera essencial para a formação de um historiador hoje?}

Josep Fontana: Eu diria que o essencial é procurar entender os problemas do mundo em que vivemos. Uma das coisas que Vives dizia aos alunos é que era importante ler jornais. Claro, todo historiador necessita, obviamente, de uma boa formação teórico-metodológica, profissional. Mas a leitura das notícias de hoje deve ser a primeira atividade de um historiador. Eu ainda faço isso todo dia. De manhã escuto rádio e vejo o noticiário da TV, depois leio os jornais locais. Ao meio-dia leio a versão eletrônica do New York Times. Ao largo disso, vou lendo revistas semanais, espanholas e estrangeiras, como The Economist, que tem a virtude de dedicar-se bastante à política internacional, bem mais que a maioria das revistas. Há muitas coisas de que necessitamos saber para entender o mundo em que vivemos. Isto para mim é uma condição essencial. O que fazemos, em última instância, deve ter uma conexão com o que as pessoas vivem. Nos últimos tempos tenho me preocupado com os resultados do trabalho dos historiadores. Na Universidade, por muito tempo, produzimos para sermos lidos por nós mesmos, por gente de nossa "tribo". Trabalhamos intensamente em muitos estudos especializados, em teses doutorais, em foco num grupo muito restrito. Temos de nos perguntar o que devemos dizer para os que não fazem parte de nosso grupo restrito, o que dizer aos não-historiadores. Hoje estou cada vez mais convencido da necessidade que temos de influir no grande público, na educação em geral, para os estudantes que vão passar pelo ensino fundamental e médio. Existe um meio público, da mídia e do poder político estabelecido, que maneja a história através de símbolos muito precisos, monumentos, heróis, discursos e comemorações cívicas. Os 
historiadores precisam entrar neste debate sobre uma história e uma memória públicas; isto é muito importante para a nossa profissão e para a democracia, senão estaremos abandonando esta área para publicitários e políticos. Por exemplo, li uma tese de doutorado sobre um problema atual e muito interessante, o trabalho era sobre a redemocratização na Espanha, sobre a transição ao final do Franquismo. Na época, os partidos de esquerda, PSOE [Partido Socialista Operário Espanhol] e PCE [Partido Comunista Espanhol], fizeram uma viragem à direita para acomodar-se à situação.

\section{Pergunta: Foi o Pacto de Moncloa?}

Josep Fontana: Sim, mas não só o pacto, foi toda uma viragem política generalizada à direita. A tese mostra como foram mudando as matérias dos cursos de verão que eram oferecidos aos militantes. Antes, eram aulas de marxismo e de como derrubar o Estado burguês; depois de um ano, passaram a ser matérias que tratavam de ensinar como administrar o Estado burguês. A tese era interessante, mas tratava das questões de forma estanque, em caixotes. Ora estudava a imprensa, noutro momento, alguns documentos oficiais. Isto é problemático, porque os historiadores precisam explicar, para que as pessoas comuns entendam os processos. É necessário se explicar uma história, construir uma narração que dê sentido às coisas e que as pessoas possam entender e tenham ferramentas para ler a atualidade. É assim que podemos entender a situação atual dos partidos de esquerda na Espanha. Este isolamento da Universidade com o mundo das ruas conduz a situações em que se tenta fabricar um tipo de ciência para o consumo interno de um pequeno grupo e no máximo atinge alguns graduandos de áreas afins. Por exemplo, estudando a historia do campesinato indígena (não apenas indígenas, mas seus descendentes e mestiços também) de muitos países latino-americanos, como o México e a Colômbia, conseguimos vislumbrar um longo processo de expropriação, que começou com a conquista europeia, mas que continua na atualidade. Há um silencio sobre a continuidade deste processo. Recebemos muitos alunos latino-americanos que estão preocupados em estudar a independência de seus países, mas pergunto a muitos deles, independência para quem? Quem ganha com este tipo de liberdade? Como se estabelecem acordos entre grupos dominantes metropolitanos e de elites locais? É comum os historiadores assumirem os discursos dos Estados Nacionais e deixarem de olhar para longos, profundos e relevantes processos sociais. Há ainda muita historia feita de cima, com o olhar na cúpula da sociedade e do Estado. Vemos ainda uma supervalorização do papel de próceres, generais e presidentes. Mas isto acontece no mundo inteiro. Sempre é necessário lembrar a nossa função. Os historiadores são educadores que devem ajudar a formar pessoas a pensarem de forma autônoma e crítica, que saibam entender e agir sobre o mundo. Quando falo em educação não penso só nas situações escolares, mas numa atuação pública geral dos historiadores (nos meios de comunicação, em órgãos governamentais e outros), que também possui um potencial pedagógico importante. 
Pergunta: Uma das questões que despertam curiosidade no Brasil são as relações entre a Catalunha e o Estado Espanhol. Podemos ver pela historiografia catalã que este é um tema que aflora em vários momentos, no século XIX e no XX, na Guerra Civil. É ainda uma questão colocada para os catalães, a possibilidade da independência?

Josep Fontana: O problema é que a dificuldade de convivência é considerável. Há falta de tolerância para a existência de uma cultura e uma língua próprias. Na época do Franquismo, por exemplo, havia uma proibição total ao uso da língua catalã. Chegou-se inclusive a proibir cartas particulares em catalão. Podia-se escrever uma carta em francês, isto não era proibido. As coisas chegaram a extremos desse tipo. Proibição total de publicação de livros e revistas em língua catalã; em determinado momento só foram autorizadas republicações do que se tinha editado em catalão, o que era absurdo e ilógico. Temos dificuldades agora a respeito da disputa política em torno do Estatuto da Generalitat [espécie de Constituição política da Catalunha, aprovada pelos parlamentos local e nacional, mas recusada pelo Tribunal Constitucional, corte com forte presença de magistrados do tempo do Franquismo]. Há uma negativa ao uso do termo "nação" dentro do Estatuto da Catalunha. É a coisa mais estúpida do mundo, não entender que uma nação é simplesmente um sentimento coletivo, de participação numa cultura comum. Isto não tem nada a ver com o Estado. Nação é um sentimento de desejo coletivo de pertencer a um grupo que se identifica culturalmente, e a forma natural política para a Espanha e para muitos países é um Estado plurinacional, que foi esboçado em alguns momentos do século XIX, mas que no século $X X$ foi violentamente reprimido, com a promoção de limpezas étnicas e travas de todo tipo. Se estudarmos a situação dos povos da Europa central e do leste antes da I Guerra Mundial, verificaremos que havia uma boa convivência de povos diferentes, organizados em Estados plurinacionais. Quando se começam a produzir nações homogeneizadas pela força, principalmente no entreguerras e durante a II Guerra Mundial, ocorrem massacres, deslocamentos, perseguições estúpidas, tudo para formar artificialmente nações, e cada nação identificada com um Estado. Há uma frase de um político soviético, que depois acompanhou leltsin, que é muito inteligente a este respeito: há no mundo uns 200 Estados e mais de 2.700 grupos étnicos e nacionais. Então, os Estados não precisam coincidir com as nações. O Estado pode ser a casa de muitas nações, e um Estado democrático precisa cumprir este respeito à diversidade. Em teoria, uma grande autonomia da Catalunha poderá ser factível com o aumento do poder gestor da União Europeia e o consequente esvaziamento político dos Estados- membros. Mas o movimento de independência poderá crescer se aumentar a intolerância dos que querem sufocar, à força, este sentimento da nação catalã. Nas Universidades aqui você pode observar que não há nenhum conflito real a respeito da língua. Cada um trabalha e ensina usando sua língua materna, e não há conflitos. O catalão é predominante nas aulas para a graduação e o castelhano é mais usado nos cursos de pós-graduação (onde há mais latino-americanos e estrangeiros). Não querer entender essas coisas e querer impor uma uniformidade artificial é algo sem sentido. 0 nacionalismo exacerbado, intolerante, parte do Estado central, que deseja padronizar a 
partir de Castela, que só admite uma diversidade local de folclores, danças e festas populares, mas o uso das línguas locais é visto como um atentado contra a nação e, neste sentido, o nacionalismo é negativo. O discurso anticatalão é uma construção de direita, e é um discurso que rende votos em outras regiões da Espanha.

Pergunta: E sobre a atual crise que vive a Europa? Há estudiosos que afirmam que existe um esgotamento do modelo político e social europeu. Como o senhor analisa esta questão?

Josep Fontana: A atual crise econômica e financeira nasce nos Estados Unidos, é de lá que vem esta crise, não da Grécia. Existe sim uma diferença entre o modelo europeu e o norte-americano. É uma diferença que vem da própria historia social europeia. Que vem de 200 anos de luta, desde a Revolução Francesa para cá, de conquistas dos direitos individuais e sociais. Efetivamente, criou-se uma sociedade europeia muito diferenciada da norteamericana no sentido da existência de maiores direitos sociais exercidos pela população: educação pública, saúde pública, aposentadoria estatal, um papel político mais importante dos sindicatos, isto compõe um modelo que os norte-americanos, com a ideologia liberal, veem como algo negativo, como um mau exemplo. Bem, agora como a crise econômica começa a se generalizar, passam a atribuir a responsabilidade a setores que não têm nenhuma responsabilidade pela crise. O FMI e o Banco Mundial já definiram o que todos os governos, mesmo os democraticamente eleitos, precisam fazer: reduzir os serviços sociais, controlar os sindicatos, reduzir as aposentadorias e salários. Trata-se de fazer com que o modelo europeu se renda ao modelo liberal norte-americano. Isto vai sim produzir uma crise social muito maior, com consequências graves. O sistema capitalista está realmente em crise, mas buscará sua sobrevivência impondo cada vez mais sacrifícios às populações. 